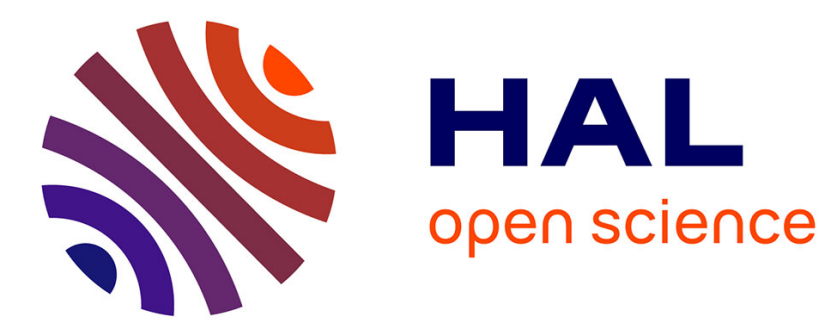

\title{
Relating ICT Competencies with Personality Types
} Vincent Ribaud, Philippe Saliou

\section{To cite this version:}

Vincent Ribaud, Philippe Saliou. Relating ICT Competencies with Personality Types. EuroSPI 2015, Sep 2015, Ankara, Turkey. pp.1-8, 10.1007/978-3-319-24647-5_24. hal-01197473

\section{HAL Id: hal-01197473 \\ https://hal.univ-brest.fr/hal-01197473}

Submitted on 11 Sep 2015

HAL is a multi-disciplinary open access archive for the deposit and dissemination of scientific research documents, whether they are published or not. The documents may come from teaching and research institutions in France or abroad, or from public or private research centers.
L'archive ouverte pluridisciplinaire HAL, est destinée au dépôt et à la diffusion de documents scientifiques de niveau recherche, publiés ou non, émanant des établissements d'enseignement et de recherche français ou étrangers, des laboratoires publics ou privés. 


\title{
Relating ICT Competencies with Personality Types
}

\author{
Vincent Ribaud $^{(\varpi)}$ and Philippe Saliou \\ Lab-STICC, Université de Brest, Brest, France \\ \{ribaud, psaliou\} @univ-brest.fr
}

\begin{abstract}
ICT competency frameworks establish the definition of competences required and deployed by ICT professionals. Job profiles articulate competencies together with an organization needs, objectives and constraints. The evolution of the software industry impacts personality trends in the profession. This work-in-progress studies the relationship between competencies, profiles and personality types.
\end{abstract}

Keywords: Personality type $\cdot$ Competency framework

\section{Introduction}

Competency frameworks, such as the e-Competences Framework [1] provides a reference of competences as required and applied at the Information and Communication Technology (ICT) workplace. The application of the European e-Competence Framework is centered upon workplace competence articulation, profiling, assessment and measurement [2]. A person's inclination towards a specific way of acquiring information or making decisions influences their preference for certain tasks and jobs [3]. Because certain jobs require certain competences, we may think that personality types and traits of software engineers are related to engineers' competences and performance. Thus we define a first research question: How can we relate personality types with employees' competencies proficiency?

Competences are sufficiently comprehensive to represent complexity and to fit variable organization structures. Customization is generally performed through the definition of various job profiles reflecting organization needs and objectives. The European ICT Professional Profiles [4] was created to define a number of representative ICT Profiles covering, at their level of granularity, the full ICT Business process. The European ICT Profiles build a consistent bridge between existing competence and profile approaches because profiles are worded in terms of capabilities needed to successfully perform a role and related to the required e-competences. Our interest is focused on four major roles involved in the development of software products: project manager, system architect, system analyst and developer. Through the study of a small set of software engineers graduated 10 years ago, we aim to empirically verify that the set of e-competences related to a role is suitable to their job occupation.

In section 2, we overview the background and related work. In section 3, we present the selected job profiles and the sample set. In section 4, we discuss the questionnaire results, and then we conclude the paper. 


\section{Background and Related Work}

\subsection{Background}

The Myers-Briggs Type Indicator (MBTI) is based on Jung's theory that people are predisposed to different alternatives in their behavior. Jung's work introduced a sequence of four cognitive functions (thinking, feeling, sensation, and intuition), each having one of two orientations (extraversion or introversion). This leads to a typology of 8 personality types. Cook Briggs and her daughter Briggs Meyer added a fourth dimension related to the way people interact with the outside world (judging or perceiving).

A competency framework is intended to foster the development of skills, either by individuals or organizations. The European e-Competence Framework (www.ecompet ences.eu/) is a reference framework of 40 ICT competences that can be used and understood by ICT stakeholders [1]. A competence is "a demonstrated ability to apply knowledge, skills and attitudes to achieving observable results [2]." Competences can be aggregated, as required, to represent the essential content of a job role or profile. On the other hand, one single competence may be assigned to a number of different job profiles [2].

Job profiles contain many components describing the essential elements of a job and how it should be performed. Jobs profiles provide a bridge between enterprises and individuals, and establish the link between an organization processes and employees' competencies. A CEN Workshop Agreement (CWA) has been established to provide a set of European ICT Professional Profiles [4]. The profiles may be used for reference, or for the basis to develop further profile generations. Profiles are structured from six main ICT Profile families: Business Management, Technical Management, Design, Devolvement, Service \& Operation, and Support.

\section{$2.2 \quad$ Related Work}

A lot of research has been performed to relate personality type with team performance, employee assignment or learning styles.

Bradley and Hebert [5] propose a model of the impact of the personality-type composition of a team on overall team performance. The model applies personality-type theory to the team-building process and then illustrates the importance of this theory by evaluating a case example of two software development teams.

Capretz [6] uses the MBTI to understand differences in learning styles and to develop teaching methods that cater for the various personality styles.

Gorla and Wah Lam [7] aims to find the relationship between personality composition of teams and the team performance in small IS teams.

Karn and Cowling [8] use the MBTI as a basis for studying how individuals interacted within the teams, and the effects of disruptive issues on the quality of work produced by the team.

Varona and al. [3] reviewed sixteen studies that explore various dimensions of human factors in software engineering. They conclude that the changes in the 
complexity of software processes and products have created new roles and demanded new skills for software engineers.

Alboaie, Vaida and Pojar [9] argue that agile software methodologies, psychology and spirituality elements, information technology developments offer possibilities to create dynamic and efficient groups.

Ylmaz, O'Connor and Clarke [10] analyzes the validity and reliability of a personality-profiling questionnaire particularly developed to assess personality types of software practitioners.

Farhangian and al. [11] investigate the effects that player personality can have on team performance in serious games.

We are not aware of research work relating competencies with MBTI types.

\section{Competencies and Profiles}

This section is intended to set up a small study for exploring research questions. Therefore this proposal needs to be validated through several studies.

\subsection{Reference Models}

\section{e-Competence Framework}

The European e-Competence Framework is based on a four-dimensional approach, based on competence areas (dimension 1) and competences (dimension 2). Dimension 3 provides level assignments that are appropriate to each competence. Dimension 4 provides short sample of knowledge and skills.

Dimension 1 is composed of 5 e-Competence areas that reflect the ICT Business process and its main sub-processes, from a broad perspective. Dimension 2 identifies and describes a set of key e-Competences for each area. We reduced the e-CF to the software development perspective because it is the scope of our study. Furthermore, descriptions in Dimension 2 provide general and comprehensive explanations of the reference e-Competences. These explanations are detailed in Dimension 3 through e-Competence proficiency level specifications. Dimension 4 is populated with samples of knowledge and skills related to e-Competences in dimension 2 . They are provided to add value and context and are not intended to be exhaustive.

\section{Proficiency Level}

Proficiency can be defined as a level of being capable or proficient in a specific knowledge, skill domain expertise or competence and is related to job performance. Proficiency indicates a degree of mastery that allows an individual to function independently in her/his job. In the e-CF, proficiency levels are described along three facets [2]: Autonomy ranging between "Responding to instructions" and "Making personal choices"; Context complexity ranging between "Structured-Predictable situations" and "Unpredictable-Unstructured situations"; Behavior ranging between "Ability to apply" and "Ability to conceive". 


\section{European ICT Professional Profiles}

Job profiles or roles "provide a comprehensive description written and formal of a job [4]'. Job profiles establish the link between an organization processes and employees' competencies. As a response to the huge number of ICT profile frameworks and profile descriptions, the CEN Workshop Agreement "European ICT Profile" defines a number of representative ICT profiles covering the full ICT business. Each profile defines a mission statement, a list of required e-competences to carry the mission, a list of deliverables, a list of tasks and some Key Performance Indicators (KPI). There are four ICT profiles that are mobilized in a software development project. The associated e-competences with the required proficiency level are presented in Table 1.

Table 1. Software development profiles based on e-CF 3.0

\begin{tabular}{|l|l|c|}
\hline ICT Profile Title & e-Competences 3.0 & Level \\
\hline \multirow{5}{*}{ Project Manager } & A.4. Product / Service Planning & 4 \\
& E.2. Project and Portfolio Management & 4 \\
& E.3. Risk Management & 4 \\
& E.4. Relationship Management & 3 \\
& E.7 Business Change Management & 3 \\
\hline \multirow{3}{*}{ System Architect } & A.5. Architecture Design & 4 \\
& A.7. Technology Watching & $4-5$ \\
& B.1. Design and Development & $4-5$ \\
& B.2. System Integration & 4 \\
\hline \multirow{3}{*}{ System Analyst } & A.5. Architecture Design & 3 \\
& B.1. Design and Development & $3-4$ \\
& E.5. Process Improvement & $3-4$ \\
\hline \multirow{5}{*}{ Developer } & A.6. Application Design & 3 \\
& B.1. Design and Development & 2 \\
& B.2. System Integration & 2 \\
& B.3. Testing & 3 \\
& B.5. Documentation Production & 3 \\
\hline
\end{tabular}

\subsection{A Case Study}

\section{A Software Engineering Master Degree}

The Master program called "Software Engineering by Immersion" provided software engineering learning by doing, with a long-term project as the foundation of all apprenticeships. Young engineers made up teams of 6; each team was led by one associate professor acting as project manager. The field of the study is to observe two teams graduated in 2006 and 2007 and led by one of the authors. We choose this sample set because graduates had completed a free MBTI test at Master studies time that was used to help to define teams' composition. Participants were aware of MBTI

This e-Competence is missing in the Developer profile definition and was added by authors. 
usage and we asked their willingness to participate to this study. Participants completed their IT bachelor 10 years ago and this period of time seems suitable to see the job paths that they followed.

A questionnaire was send to the participants concerning her/his current occupation, how job profile related e-competences are mobilized with a self-assessment of the proficiency level. Participants were asked to run a free MBTI test to ensure that their personality type was accurate.

\section{Participants' Personal Data}

Table 2 and 3 present participants' information: gender, age, job profile, MBTI type.

Table 2. Information on Team 1 (graduated in 2004 and 2006)

\begin{tabular}{|l|l|l|l|l|}
\hline ID & Gender & Age & Current occupation & MBTI Type \\
\hline 1A & Male & 32 & System Architect & ISTJ \\
\hline 1B & Male & 41 & System Analyst & ESFJ \\
\hline 1C & Female & 33 & Project Manager & INTP \\
\hline 1D & Male & 34 & Developer & INFP \\
\hline 1E & Male & 33 & System Analyst & ISTP \\
\hline $1 \mathrm{~F}$ & Male & 35 & System Architect & INTJ \\
\hline
\end{tabular}

Table 3. Information on Team 2 (graduated in 2005 and 2007)

\begin{tabular}{|l|l|l|l|l|}
\hline ID & Gender & Age & Current occupation & MBTI Type \\
\hline 2A & Male & 32 & Developer & ESTP \\
\hline 2B & Male & 32 & Developer & ISFJ \\
\hline 2C & Female & 32 & Project Manager & INFP \\
\hline 2D & Male & 31 & System Architect & ISTP \\
\hline 2E & Male & 32 & Project Manager & INFJ \\
\hline 2F & Female & 31 & System Analyst & ISFP \\
\hline
\end{tabular}

The sample set distribution is compatible with a study conducted by Lyons [12] that included 1229 computer professionals employed by 100 companies. In our set, $75 \%$ were men and $25 \%$ were women (vs. $83 \%$ and $17 \%$ ); $75 \%$ were introverts (vs. $57.8 \%$ ); $58.3 \%$ were sensors (vs. $63.8 \%$ ). We have only $50 \%$ thinkers (vs. $85.4 \%$ ) and $41.8 \%$ judgers (vs. $79.4 \%$ ) but the study is 30 -years old and our set is composed from $\mathrm{Y}$ generation individuals.

\section{Participants' Questionnaire Results}

We proposed to participants to assess if a general set of e-competences was useful for the jobs they occupied until now and also to assess if the dedicated set related to her/his current occupation. For each e-competence, participants selected a value ranging from Totally Useful, Largely Useful, Partially Useful, Not Useful. When a competence was considered as being Totally or Largely Useful, participants had to selfassess the proficiency level using the definition given in the e-CF document [1]. 
The general set comprises main e-competences related to the A. PLAN and B. BUILD areas. Software development is less concerned with the areas C. RUN and D. ENABLE. Only the Project Manager profile is concerned with the E. MANAGE area. The general set is made of: A.4 Product / Service Planning, A.5 Architecture Design, A.6 Application Design, A.7 Technology Trend Monitoring, B.1 Design and Development, B.2 System Integration. Dedicated sets are those given in Table 1.

Table 4. Competencies" proficiency.

\begin{tabular}{|l|l|l|l|l|l|l|l|l|l|l|l|l|l|l|l|l|}
\hline ID & MBTI & Job & A.4 & A.5 & A.6 & A.7 & B.1 & B.2 & B.3 & B.5 & C.4 & E.2 & E.3 & E.4 & E.5 & E.7 \\
\hline 1A & ISTJ & Arc. & $2-3$ & 4 & 3 & 3 & 3 & 3 & - & - & - & - & - & - & - & - \\
\hline 1B & ESFJ & Ana. & 2 & 3 & 2 & 4 & 3 & 2 & - & - & - & - & - & - & - & - \\
\hline 1C & INTP & Man. & 4 & 3 & 2 & - & 3 & 2 & 3 & 3 & 3 & 3 & 2 & 3 & - & 3 \\
\hline 1D & INFP & Dev. & - & 3 & 3 & 3 & 3 & 3 & 3 & 3 & 3 & - & - & - & - & - \\
\hline 1E & ISTP & Ana. & 2 & 3 & 3 & 3 & 3 & 3 & - & - & - & - & - & - & 3 & - \\
\hline 1F & INTJ & Arc. & 2 & 3 & 2 & 3 & 3 & 2 & - & - & - & - & - & - & - & - \\
\hline 2A & ESTP & Dev. & - & 4 & 3 & 3 & 3 & 3 & 2 & 2 & 2 & - & - & - & - & - \\
\hline 2B & ISFJ & Dev. & - & 3 & 3 & 3 & 3 & 3 & 3 & 3 & 3 & - & - & - & - & - \\
\hline 2C & INFP & Man. & 3 & 3 & 2 & - & 2 & 2 & 3 & 3 & 2 & 3 & 2 & 3 & - & 4 \\
\hline 2D & ISTP & Arc. & 3 & 5 & 3 & 5 & 3 & 3 & - & - & - & - & - & - & - & - \\
\hline 2E & INFJ & Man. & 4 & 4 & 3 & 3 & 3 & 3 & 4 & 4 & 3 & 3 & 3 & 3 & 3 & 3 \\
\hline 2F & ISFP & Ana. & 2 & 3 & 3 & - & 2 & 2 & - & - & - & - & - & - & - & - \\
\hline
\end{tabular}

\section{$4 \quad$ Aggregation of Results}

Table 5 presents a comparison between the average of the whole set with the average of subsets grouped on MBTI trends. Values that differs significantly are bolded.

Table 5. Proficiency self-assessment grouped by MBTI type

\begin{tabular}{|l|l|l|l|l|l|l|l|l|l|l|l|l|l|l|l|}
\hline MBTI & Nb & A.4 & A.5 & A.6 & A.7 & B.1 & B.2 & B.3 & B.5 & C.4 & E.2 & E.3 & E.4 & E.5 & E.7 \\
\hline Whole & 12 & 2,67 & 3,42 & 2,67 & 3,44 & 2,83 & 2,58 & 2,73 & 2,64 & 2,55 & 3,00 & 2,33 & 3,00 & 3,00 & 3,33 \\
\hline E & 3 & $\mathbf{2 , 0 0}$ & 3,33 & 2,67 & 3,50 & 2,67 & 2,33 & $\mathbf{2 , 0 0}$ & $\mathbf{2 , 0 0}$ & $\mathbf{2 , 0 0}$ & & & & & \\
\hline I & 9 & 2,86 & 3,44 & 2,67 & 3,43 & 2,89 & 2,67 & 3,00 & 2,88 & 2,75 & 3,00 & 2,33 & 3,00 & 3,00 & 3,33 \\
\hline N & 5 & $\mathbf{3 , 2 5}$ & 3,20 & 2,40 & 3,00 & 2,80 & 2,40 & $\mathbf{3 , 2 5}$ & $\mathbf{3 , 2 5}$ & 2,75 & 3,00 & 2,33 & 3,00 & 3,00 & 3,33 \\
\hline S & 7 & 2,20 & 3,57 & 2,86 & 3,67 & 2,86 & 2,71 & 2,43 & 2,29 & 2,43 & & & & 3,00 & \\
\hline T & 6 & 2,60 & 3,67 & 2,67 & 3,60 & 3,00 & 2,67 & 2,60 & 2,40 & 2,60 & 3,00 & 2,00 & 3,00 & 3,00 & 3,00 \\
\hline F & 6 & 2,75 & 3,17 & 2,67 & 3,25 & 2,67 & 2,50 & 2,83 & 2,83 & 2,50 & 3,00 & 2,50 & 3,00 & 3,00 & 3,50 \\
\hline J & 5 & 2,50 & 3,40 & 2,60 & 3,40 & 3,00 & 2,60 & 3,00 & 2,75 & 2,75 & 3,00 & 3,00 & 3,00 & 3,00 & 3,00 \\
\hline P & 7 & 2,80 & 3,43 & 2,71 & 3,50 & 2,71 & 2,57 & 2,57 & 2,57 & 2,43 & 3,00 & 2,00 & 3,00 & 3,00 & 3,50 \\
\hline
\end{tabular}

Extraverts (E) have a proficiency self-assessment significantly lower than Introverts (I) for competences A.4 Product / service Planning, B.3. Testing, B.5. Documentation Production, C.4 Problem Management. A possible explanation is that these competences involve methodic and routinely tasks that Extraverts tend to avoid. 
Intuitive individuals $(\mathrm{N})$ have a proficiency self-assessment significantly higher than Sensing individuals (F) for competences A.4 Product / service Planning, B.3. Testing, B.5. Documentation Production. A possible explanation is that these competences also involve abstract, methodic and precise tasks that Intuitives like.

There are no significant differences neither between Thinkers $(\mathrm{T})$ and Feelers $(\mathrm{F})$ nor between Judgers $(\mathrm{J})$ and Perceivers $(\mathrm{P})$.

Since only few individuals were queried, it is difficult to discuss about classical MBTI grouping such as intuitive-thinkers (NT), intuitive-feelers (NF), sensingthinkers (ST), and sensing-feelers (SF). We need a larger set to draw observations.

Table 6 presents a comparison between the average of the whole set with the average of subsets grouped on job profiles. Values that differs significantly are bolded.

Table 6. Proficiency self-assessment grouped by job profiles

\begin{tabular}{|l|l|l|l|l|l|l|l|l|l|l|l|l|l|l|l|}
\hline Role & Nb & A.4 & A.5 & A.6 & A.7 & B.1 & B.2 & B.3 & B.5 & C.4 & E.2 & E.3 & E.4 & E.5 & E.7 \\
\hline Whole & 12 & 2,67 & 3,42 & 2,67 & 3,44 & 2,83 & 2,58 & 2,73 & 2,64 & 2,55 & 3,00 & 2,33 & 3,00 & 3,00 & 3,33 \\
\hline Man. & 3 & $\mathbf{3 , 6 7}$ & 3,33 & 2,33 & 3,00 & 2,67 & 2,33 & 3,33 & 3,33 & 2,67 & 3,00 & 2,33 & 3,00 & 3,00 & 3,33 \\
\hline Ana. & 3 & 2,00 & 3,00 & 2,67 & 3,50 & 2,67 & 2,33 & & & & & & & 3,00 & \\
\hline Arc. & 3 & 2,33 & $\mathbf{4 , 0 0}$ & 2,67 & $\mathbf{4 , 0 0}$ & 3,00 & 2,67 & & & & & & & & \\
\hline Dev. & 3 & & 3,33 & 3,00 & 3,00 & 3,00 & 3,00 & 2,67 & 2,67 & 2,67 & & & & & \\
\hline
\end{tabular}

Recall that the general set comprises main e-competences related to the A. PLAN and B. BUILD areas. Managers are obviously more concerned with competence A.4 Product / Service Planning while Architects are more involved with competences A.5. Architecture Design and A.7. Technology Watching. There are no others significant differences.

\section{Conclusion}

We made the hypothesis that personality types and traits of software engineers are related to engineers' competences. For the first research question that tries to relate personality types with employees' competencies proficiency, we did not observe significant results apart those that are relatively obvious and predictable. Since the sample set is small, we may expect better observations from a larger set.

Regarding the second question related to the suitability of job profiles' definition, participants agreed on the required competencies whatever their MBTI types.

\section{References}

1. CEN. CWA 16234-1:2014. European e-Competence Framework 3.0- Part 1: A Common European Framework for ICT Professionals in All Industry Sectors. CEN, Bruxelles (2014)

2. CEN. CWA 16234-2:2014 - Part 2: User guidelines for the application of the European e-CF 3.0. CEN, Bruxelles (2014) 
3. Varona, D., Capretz, L.F., Piñero, Y., Raza, A.: Evolution of software engineers' personality profile. ACM SIGSOFT Software Engineering Notes 37(1), 1-5 (2012)

4. CEN. CWA 16458:2012. European ICT Professional Profiles. CEN, Bruxelles (2012)

5. Bradley, J.H., Hebert, F.J.: The effect of personality type on team performance. Journal of Management Development 16(5), 337-353 (1997)

6. Capretz, L.F.: Implications of MBTI in software engineering education. ACM SIGCSE Bulletin 34(4), 134-137 (2002)

7. Gorla, N., Lam, Y.W.: Who should work with whom?: building effective software project teams. Communications of the ACM 47(6), 79-82 (2004)

8. Karn, J., Cowling, T.: A follow up study of the effect of personality on the performance of software engineering teams. In Proceedings of the 2006 ACM/IEEE International Symposium on Empirical Software Engineering, pp. 232-241 (2006)

9. Alboaie, L., Vaida, M.F., Pojar, D.: Alternative methodologies for automated grouping in education and research. In: Proceedings of the CUBE International Information Technology Conference, pp. 508-513 (2012)

10. Yilmaz, M., O'Connor, R.V., Clarke, P.: An exploration of individual personality types in software development. In: Barafort, B., O'Connor, R.V., Poth, A., Messnarz, R. (eds.) EuroSPI 2014. CCIS, vol. 425, pp. 111-122. Springer, Heidelberg (2014)

11. Farhangian, M., Purvis, M.K., Purvis, M., Savarimuthu, B.T.R.: Modelling the effects of personality and temperament in small teams. In: Balke, T., Dignum, F., van Riemsdijk, M., Chopra, A.K. (eds.) COIN 2013. LNCS, vol. 8386, pp. 25-41. Springer, Heidelberg (2014)

12. Lyons, M.L.: The DP psyche. Datamation 31(16), 103-110 (1985) 